\title{
Universities in Africa: Working on Excellence for Whom? Reflections on Teaching, Research, and Outreach Activities at African Universities
}

\author{
Dr. Jacques Zeelen, Associate Professor \\ Department of Lifelong Learning, University of Groningen, the Netherlands
}

$\&$

Former Head of the Department of Adult Education at the University of the North in South Africa

Received: August 11, 2012

Accepted: September 17, 2012

Online Published: September 21, 2012

doi:10.5430/ijhe.v1n2p157

URL: http://dx.doi.org/10.5430/ijhe.v1n2p157

\begin{abstract}
This article discusses the current dynamics at African universities concerning the quality of teaching, the role of research, the level of community outreach, and the position of higher education in the educational sector as a whole. Points of reference are experiences at the University of the North in South Africa as well as experiences at universities in other African countries such as Uganda, Tanzania, Mozambique, and Ghana.

One of our central conclusions is that the system of education in Africa in general, and higher education in particular, is highly dysfunctional, especially in terms of wasted human capacity as well as financial resources. African higher education institutions cannot close their eyes to the immense skills shortage and the frightening percentages of (youth-) unemployment. This leads to the recommendation that the responsibilities of a university concerning the generation of relevant new knowledge, preparing students adequately as active citizens for the challenges in the labour market, contributing to the development of communities, and fostering critical thinking need to be given high priority.
\end{abstract}

Keywords: Higher education, African universities, Lifelong learning

"Every day we can see the university buildings. We always wonder if this big institution with all its knowledge cannot help us! But we do not know how to ask, and we are afraid that they will send us away."

\section{Introduction}

The statement above was made by a man from Ga-Mothapo (see Stevens, 2000, p. 53), a settlement in South Africa, a few kilometres away from the University of the North (UNIN), now called the University of Limpopo. He was interviewed in 1994 by Hetty Stevens, the first exchange student at UNIN from the University of Groningen (RUG) in the Netherlands, during her research into the needs for adult education in the communities around the university. His statement expresses the enormous psychological distance from the university, despite being so near, as well as the urgent need of people in the communities. At the same time, the statement reflects the role of this university in the apartheid era, as indicated by White (1997, p. 1): "The University of the North was created as a political, not an educational, necessity." The university served mainly as an ideological legitimization for an inferior kind of higher education directed at black people and civil servants for the homeland administration. The quality of teaching and research was questionable, and the curricula were often not tailored to the urgent needs of the community (Rampedi, 2003).

The issue of the relevance of a university for communities such as Ga-Mothapo is a crucial one for all universities in Africa. This paper discusses questions about the quality of teaching, the role of research, the level of community outreach, and the position of higher education in the educational sector as a whole. Points of reference are the author's experiences gained at the University of the North in the period from 1997 - 2004, as well as more recent experiences while working with African colleagues at universities in other countries, such as Uganda, Tanzania, Mozambique, and Ghana. In addition, some reflections on current developments in universities in the so-called developed North will be added, to show that in a certain way we have to deal with more universal issues than the isolated cases concerning what a quality university should be. 
Assessing universities can be done with different eyes and from several perspectives. An interesting perspective is offered by the Spanish sociologist Castells (2001), who expressed his approach at a conference in Johannesburg. He discussed the role of a university from a historical perspective. Castells speaks of the following four functions of a university:

1) The formation and dissemination of ideology; 2) The selection of dominant elites; 3) The generation of new knowledge; and 4) The training of a skilled labour force (including contributing to the development of society). Besides these functions formulated by Castells, in my view, an additional fifth function needs consideration as well: The role of the university as a place for independent and critical thinking that challenges the status quo of the specific society where it functions.

There are several examples specific to South Africa that illustrate this last function of a university. Communities at the University of the North and, for instance, the University of the Western Cape, in opposition to the formation and dissemination of the apartheid ideology, have impressively played this role during apartheid. Other examples are the University of Development Studies (UDS) in Tamale, Ghana which seeks to challenge traditional universities' view of education as a privilege to be enjoyed by the few for their own benefit (Amenumey, 2007), as well as the University of Dar Es Salaam's REDET (Research and Education for Democracy in Tanzania) that strives to "support and promote the process of creating politically competent citizens" (Mhina \& Killian, 2009, p. 3).

Although this gives a first idea of how we could look at a university, there is much more to say about this. For instance: Which functions were dominant in certain historical periods and what kind of functions are more prominent in Africa today? Furthermore, what kind of contradictions and possible tensions exist between the different functions of a university? It is obvious, for instance, that there exists a deep contradiction between the formation and dissemination of ideology and the university as a place for critical and independent thinking. Moreover, an important question is how to combine the generation of new knowledge with the training of a skilled labour force. Not all these questions will be extensively discussed in this article; however, some reflections on the functions of a university will be used to explore key problems faced by African universities.

\section{Mission statements}

It is relevant to refer to a few mission statements of African universities. How are the intended functions of a university being formulated? The first one is the mission statement of the University of Limpopo:

"A world class African university, which responds to education, research and community engagement needs through partnerships and knowledge generation - continuing a long tradition of empowerment"

In addition, the mission statement of Makerere University in Kampala, Uganda:

"To provide innovative teaching, learning, research, and services responsive to National and Global needs"

And lastly, the mission statement of the University of Dar-Es-Salaam, Tanzania:

"The unrelenting pursuit of scholarly and strategic research, education, training and public service directed at attainment of equitable and sustainable socio-economic development of Tanzania and the rest of Africa"

Some of the earlier functions are reflected in these mission statements, some are not. Two statements refer to Africa explicitly, especially in terms of an African university. Common however is the functional orientation towards excellence in three domains: teaching, research and community outreach.

With these mission statements, the profile of an excellent African university is created. The challenge is how to put this appealing aspiration into practice. What dynamics facilitate the implementation, and what trends are working against a successful fulfilment of these ambitions? The following discussion is based on four statements as well as on subsequent examples and experiences that illustrate the main challenges in putting these mission statements into practice. It is important to note here that the author's experiences are selective in terms of countries and faculties, where he worked mainly in the area of the social sciences and humanities. In other words, what will be presented is not the state of the art of African universities supported by representative empirical evidence. However, it is intended that these considerations concerning the current dynamics in African universities, being stimulated by an intensive dialogue with African and Dutch colleagues, will have some exemplary value for a wider context relating to African universities.

\section{Four Statements about Current Dynamics at African Universities}

1: African universities are predominantly teaching institutions with weak connections to the labour market;

2: The existing lack of research culture and inadequate supervision has a negative effect on the quality of the research; 


\section{3: Links with communities are under pressure, divisions are widening; and}

\section{4: The massification of higher education leads to the question: Are parts of the student population at the right place?}

The statements refer to current trends and dynamics which hamper the realization of the appealing mission of an African university excelling in teaching, research, and outreach. These statements will be supported by some personal observations, experiences, references to relevant sources, and suggestions.

\section{1: African universities are predominantly teaching institutions with weak connections to the labour market.}

Visiting African universities, one can see and meet a lot of students. Recently, at Makerere University in Kampala, I was impressed by the overcrowded corridors, long queues of students waiting for their lunch, and big groups trying to make photocopies. Colleagues at that university complained a lot about the full lecture halls, often packed with 600-800 students, and of course about their mammoth task of marking all these tests. Visits to other places such as the University of Dar-Es-Salaam gave me a similar impression. This can be supported by recent statistics. For about four decades, enrollment in Sub-Saharan Africa universities grew on average of $8.6 \%$ annually, and education planners are faced with the challenge of recruiting staff for systems that are doubling in size every eight years (Bruneforth, 2010). Besides the high number of undergraduates, there is also a growing number of postgraduate students. The financial systems of higher education pushed this trend further upward and, in addition, there are many forms of distant learning as well. Universities start satellite campuses and are even competing with each other in smaller cities. In countries such as Tanzania, Uganda, and Ghana private universities are mushrooming. For example, according to the Ugandan National Council for Higher Education (NCHE), in 2010 Uganda had 29 universities and other 152 tertiary institutions. All this considering that up to 1988, Uganda had only one university - Makerere (Kasozi, 2010). In my work as a member of international evaluation committees, it is not unusual to see, for instance, in Ghana and Tanzania, the names of same lecturers at those different campuses and new private universities. It seems that because of the vast lack of university financial resources, a group of lecturers is travelling from one place to the other to deliver the same lectures to the new groups of students - a practice known as moonlighting. Weekend, evening, and even night classes are booming at institutions for higher education, for instance, and also in Kenya, as a colleague from Nairobi recently mentioned. Higher education seems to have become big business. There is a huge market for the admission of students; the question is, however, if there is a labour market awaiting those students when they complete their studies. And indeed, the question is whether the lecturers have the dedication and capacity to teach in such an educational environment.

This massification of higher education is having a very negative impact on the quality of education. First of all, it is important to mention a bit of history on where African universities are coming from. Referring to the earlier noted functions of a university, African universities were for a long time dominated by the formation and dissemination of colonial ideology, the selection of dominant elites, and the training of a selected group of civil servants (see also Teferra \& Altbach, 2004). Generating new knowledge and being a place for critical thinking was completely out of the picture. The system and approach of Bantu education in South Africa is a clear example of it. The Brazilian scholar in adult education, Paulo Freire (1972), called this type of education the banking concept of education: an instrument of oppression. The banking concept means leading the student to memorize mechanically the offered content. According to Freire, this approach turns students into "containers" to be filled by the teacher without honouring the voice and input of the student.

Massification of education has historical roots in Africa. Three main factors contribute to the current phenomenon where universities run well over capacity. One, there was a need to fill a sizeable unmet demand for civil servants and other professionals just before and after independence. The availability of employment opportunities then meant that as many students as possible could enrol and still get a job upon completion. Two, there has been an explosion of population growth in the last few decades. According to the World Bank (2008), African population will double its current size by 2036. According to the United Nations estimates, Africa had just over 277 million people in 1960 . That figure was estimated at 995 million people in 2011, a nearly four-fold increase in half a century (UNESA, 2004). Three, the expansion and improvement of standards at both primary and secondary schools has led to the inevitable increase in enrolment at tertiary institutions. For example, Musisi (2002 in Teferra \& Altbach, 2004) states that Uganda had 510 secondary schools in 1980; by 1996, the country had 610 schools hosting 256,000 pupils. In that country, primary school enrolment rose from 2.2 million in 1986 to 6.8 million in 2003 (Openjuru, 2010). Mkude et al. (2003) report similar findings in Tanzania, and the student figures, all pointing to an upward trend, are comparable in other African countries.

Despite encouraging developments in the last few decades, this legacy, and especially the lack of generating new knowledge and critical thinking, is very much existent in many universities. Under the problematic conditions of the 
massification of higher education mentioned earlier, such as overcrowded lecture halls and a vast lack of resources, the implementation of a quality education, including stimulating critical thinking, is increasingly becoming a challenge. The following conditions still characterize many higher education institutions: One-way traffic between lecturers and students, working predominantly with notes and not with original publications; the absence of a reading culture; the use of outdated teaching and reference materials; teaching materials without links and examples referring to African realities (Kanyandago, 2010); neglect of the local African languages (Ramani \& Joseph, 2002); and teaching programmes which are often test- and exam-oriented (Openjuru, 2010), with sometimes the unintended negative consequences of plagiarism and fraud.

Even with these shortcomings, some students are obtaining their degrees. As indicated earlier, however, what these degrees mean in terms of students' competencies and preparedness for the challenges of the formal and informal labour market is, in many cases, debatable. Some institutions are already taking steps towards curbing the situation. At Sokoine University of Agriculture in Morogoro (Tanzania), the university administration strongly encouraged the teaching of income-generating skills because many of their graduates could not be absorbed by the formal labour market and, consequently, ended up unemployed (Jahn \& Zeelen, 2003; for a broader view see also Al-Samarrai \& Bennell, 2006). This means that the function of higher education to prepare and train students to become leading reflective professionals, engaged in the development of their country, is problematic and needs to be further discussed.

2: The existing lack of a research culture and inadequate research supervision has a negative effect on the quality of the research.

An important element which also affects the quality of education is the marginal role of research at most African universities. A strong research component would create the possibility of nourishing the teaching programmes with new knowledge, experiences from elsewhere, and current academic debates.

The argument that "public investment in universities and colleges brings meagre returns compared to the returns for primary and secondary education and higher education magnifies inequalities" (World Bank, 2000, p. 10) has not helped the strengthening of research efforts in African universities. Universities see their main source of funding, the government, withdraw much of their support in the 1970s and 1980s due to economic realities of the time (Musisi \& Muwanga, 2003), using arguments such as mentioned just above.

The reason for the marginal role of research originates from the aforementioned history of African universities. Coupled with this are the tremendous changes that have happened in the higher education terrain in Africa in the last few decades. An explosion of population, poor funding of higher education, overcrowded classes, and poor teaching materials have all brought about challenges to higher education that allow too little room for research activities. As an example, many higher education institutions in Africa are now catering to double the capacity they were built for (Sawyerr, 2004).

Historically, the universities in Africa, immediately after independence, started without a culture supportive of research. Most universities started as teaching institutions often affiliated with a metropolitan university of a colonial power, and it seems to be difficult, despite the explicit ambition formulated in the mission statements, to strengthen the role of research, to create a vibrant research culture, and to implement community oriented research activities.

During my work at UNIN, I was surprised to see that, in terms of identity, many lecturers saw themselves not (also) as researchers but mainly as teachers. This also became visible as quite a number of colleagues just popped in to deliver their lectures and disappeared afterwards. Not engaging in research, however, also has something to do with self-confidence. I remember one of our staff members at the School of Education honestly telling us that for a long time he was "...thinking that research is a monster which can only be tamed by highly intelligent white people" (see: Zeelen, 2004, p. 7; Zeelen, 2003). Colonial education has undermined the self-confidence and self-esteem of many learners and staff members. Its legacy was also visible to me in the way some seniors who had obtained their degrees and titles in the old system were using the word "research" to intimidate the so called uneducated. Freire analysed this type of phenomenon by stating that the oppressed run the risk of turning into oppressors themselves.

Building research capacity and raising the quality of research supervision are thus crucial for further development of African universities. In that context, Jonathan Jansen, now Vice-Chancellor at the University of the Free State, discussed, in 2002, the issue of changing research cultures at the so-called Historically Disadvantaged Universities in South Africa (Jansen, 2002). One of the problems he pointed out was that “...the sad reality is that most deans and heads of departments (and indeed many of our vice-chancellors) are such poor researchers themselves that they cannot make the (necessary) kind of demands on new researchers in the faculties for sheer lack of credibility" (p. 49). Other universities in Africa sometimes see the problem of the older generation not often giving way to the younger, more 
talented researchers. The quality of supervision of postgraduate research (Masters and Ph.D.) is often weak, because many supervisors don't have vast research experience themselves. To break the cycle of reproducing research mediocrity by developing the research skills and attitudes of talented students and young researchers seems to be one of the main challenges for the coming years.

In this context, international collaboration has been playing a positive role for quite some time in enhancing this type of research capacity building (see for instance Zeelen and Van der Linden, 2009). A fruitful collaboration in the last decade has been that of the University of Groningen (where I currently work), the University of Limpopo, Eduardo Mondlane University in Maputo, Uganda Martyrs University, and Mzumbe University in Tanzania, resulting in new teaching and research efforts in (adult) education, public administration, and community oriented research (see among others: Rampedi, 2003; Sitoe, 2006; Angucia, 2010; Mollel, 2010; Zeelen et al., 2010).

\section{3: Links with communities are under pressure; divides are widening.}

Community outreach has quite a tradition in several African universities in terms of community services, collaborative research projects, and field attachments. In the humanities, especially the departments of adult education and extramural studies allow people from the communities to take part. This could partly be explained by the fact that many African universities, especially those developed immediately after independence, were founded on the notion of the "developmental university" (see Sawyerr, 2004). In some ways, education was expected to reflect and sustain national priorities, aims, and aspirations of many African countries. In addition, it has to translate the national ideology into curriculum (Nasongo \& Musungu, 2009; Njoroge and Bennaars, 1986). Examples of this view of education can be found in Julius Nyerere's educational philosophy on "Education for Self-reliance." The desire for strong ties with communities is meant to be beneficial to both parties. That the university would benefit from real life experiences while enriching their academic understanding of the subject matter and the community would result in knowledge they need for their own development: "Our education must therefore inculcate a sense of commitment to the total community" (Nyerere, 1968, p. 239; see also Mulenga, 2001). This type of work, however, is increasingly under pressure due to several factors. Growing budget constraints in higher education has, to a large extent, hampered efforts for higher education to achieve its goals (Altbach \& Peterson, 1999). Funding remains one of the main challenges to university - community engagement. For instance, the Department of Adult Education at the University of Ghana in Accra has a long tradition of community involvement. Some years ago, I attended some of their activities in the remote rural areas where they combine literacy training and skills for self-employment with an impressive role for the community. My colleagues told me that they will soon have to terminate these activities. There is no funding any longer, and the department is now more directed to the profitable activity of distance education, and, unfortunately, illiterate people would definitely not have access to these activities. This will mean that the divide between the learning rich and the learning poor will be deepened (Van der Veen \& Preece, 2005). Another pressure put on my colleagues in Accra is to publish more, and some are thinking of quitting the university. Of course, there is nothing wrong with publishing, but the spectrum of publications and the question of how the new knowledge gained is essential. For instance, it would be very relevant to bring the adult education experiences gained in rural Ghana into a scientific and public discourse.

On this point, I would like to refer to the current developments in the so-called North. Academic staff in the humanities and social sciences is under enormous pressure to publish exclusively in top international journals. In certain faculties, even books and chapters seem to have become irrelevant. This policy leads to - what I call - the calculating researcher, one who is looking for a shortcut from the data to the publication of an article. This means that complicated and time-consuming community oriented research gets more and more marginalized, and many scholars who were engaged in this work end up leaving the university. In our society, the inward looking attitude of the university is becoming increasingly under fire. People from industries are asking why the university is not contributing to the knowledge society; as well, other professionals from education and health are complaining about the lack of relevance of research in the Ivory Tower. This trend has also arrived in Africa, and it would be tragic if universities would go the same route. After all, Africans know where the ivory goes.

Besides extramural activities, there is also another type of work connecting universities with the community. It was visible, for instance, at the Eduardo Mondlane University in Maputo and Mzumbe University in Tanzania, where university staff are engaged as researchers and consultants contributing to development by working for NGOs and other institutions or organisations. Most of these activities are relevant, but the problem is that this type of work is often not visible in the academic sense of developing new knowledge in the context of transparency and accountability. Most of the publications about these activities are not accessible or not being used effectively. The question is how to integrate these activities into academic work. If not, these activities will continuously absorb intellectual energy from the academic staff. 
In this discussion of research, community, and calculating researchers, it should also be mentioned what was brought up by a Ph.D. student from Uganda Martyrs University. He was telling the story of villagers around the university who were complaining that after years and years of filling out questionnaires from university researchers, they decided to refuse to do this any longer. Their statement was very clear: Why fill out these papers if nothing ever happens afterwards? I wonder if our man from Ga-Mothapo was also the victim of what I would call data-robbers.

For the coming period, it will be extremely important to improve the publication capacity of African universities in international, African, and national journals without falling into the trap of an inward looking university as so many universities in the North are doing. It is the challenge to combine the earlier mentioned functions of a university with generating new knowledge and contributing to the development, for example, of rural communities. In those communities there exists a tremendous potential for development, the use of endogenous knowledge, and the enhancement of collective learning experiences (Kanyandago, 2010). We need more practice-oriented researchers to develop partnerships with practitioners in fields such as health and education, NGOs, local businesses, government departments, and civil society. To make this possible, the quality of the researchers and the research itself has to be improved substantially. In that respect, more attention should be paid to training students and researchers in participatory research methodologies (see for instance Boog et al., 2008).

4: The massification of higher education leads to the question: Are parts of the student population at the right place? Earlier we discussed the massification of higher education. Partly as a result of unfavourable conditions, the dropout rates (especially in the first years) are substantial. At some universities, colleagues reported figures of $40 \%$ and higher. As a response, some institutions are creating so-called "bridging programmes" to support disadvantaged students' efforts to gain acceptance into a university. In his reconstruction of recent developments at Makarere University in Kampala, Mahmood Mamdani (2007) comes to the conclusion that we have to ask ourselves whether a substantial group of students is actually at the right place. In his opinion, a university should always be research-oriented. For many students at Makerere, vocational programmes in the context of a community college to be established separate from the university, would be much more appropriate. This would create opportunities, in Mamdani's view, to reduce the high numbers of students on the campus. Moreover, this would generate more conducive conditions to develop the quality of teaching, research, and outreach.

In my view, this is an important suggestion. One should be aware, however, that in vocational programmes, similar dynamics are at stake. In many vocational programmes in African countries, the curriculum is still very academically oriented, often with weak practical skills orientation not geared to the labour market (see for instance Kibwika, 2006). In Uganda, colleagues from a technical school near Mbarara told me about the worrying trend of raising the standards for admission by demanding higher math and English proficiency. In my view, this will surely lead to the exclusion of talented learners for technical and agricultural professions.

This brings us to a deeper layer of discussing the position of higher education in the overall landscape of educational efforts. Research executed by the Early School Leaving in Africa Project (ESLA) revealed alarming dropout rates in primary and secondary education in Africa (Zeelen et al, 2010). For instance, about ten million children drop out of primary school each year (UNESCO, 2011) and less that 30\% of all children successfully complete secondary schooling (Lewin, 2009; Lewin \& Akyeampong, 2009). In most Sub-Saharan countries, the figures are dramatic and, as a result, youth unemployment is huge, for instance in Kenya (Mwinzi \& Kelemba, 2010). According to the World Bank, in 2009, Uganda carried an 83\% youth unemployment rate (World Bank, 2009). As a consequence, many young people are vulnerable to crime and (political) abuse (see Angucia, 2010). One conclusion to be drawn here is that the educational system in most countries is very much academically oriented with a marginal role for vocational tracks. Furthermore, almost across the board in urban (but also in remote rural) areas, parents, teachers, and learners themselves look at the university as the place to go. This is also a matter of mindset, probably influenced by (post-) colonial legacies. Often, people who are leaving the academic track are seen as losers, even in a time when a growing number of people with degrees are unemployed. In a study about university students' attitudes in Nigeria, Labeau had rather a depressing conclusion:

"Even if the university as a direct passport to becoming an elite in the country is no longer a reality, our interviews revealed clearly that higher education as a prerequisite to social climbing is an ideology that is still widely supported in Nigeria." (Lebeau, 2000 in Sawyerr, 2002, p. 15).

The prospects and lures of getting a better job and enjoying a meaningful life after university graduation still play a major part of the academic perception. The great pressure applied to young people to obtain a university degree exerts even more pressure on institutions of higher learning to enrol more students. A tragic example of this pressure happened in January 2012. In a desperate attempt to claim a place for her child at the university, one parent was crushed to death in a stampede at the gates of the University of Johannesburg's Bunting Road campus. Several other people were also injured in the incident which happened after thousands of secondary school leavers started assembling early 
one Monday morning to try to enter their late registrations at the University of Johannesburg (Mail \& Guardian, 10 Jan. 2012).

This is one of the reasons why many authors in the recent ESLA publication suggest creating a greater number of streams at secondary schools to accommodate the different talents of the learners (Zeelen et al, 2010) as well as to invest much more in renewed concepts of guidance and counselling to mentor young people in their educational and job choices. The spectrum of talents is much wider than just academic capabilities; for instance, there are many learners who have rich talents for technical, health care, agricultural, and other domains. It is unfortunate that those types of profession, which are essential to the improvement of the living conditions in African countries, are not getting the attention they deserve. It seems that the drive towards higher education often has more to do with the goals of social mobility and obtaining status than with the intrinsic motivation and capabilities for academic knowledge (Minnis, 2006). Using concepts of Pierre Bourdieu (1991), one could say that people are not so much striving for cultural capital, but rather more for obtaining symbolic capital. In addition, quite often, parents are pushing their children in the direction of a university without looking at their children's specific talents and prefe-rences. It is hardly surprising that these students have motivational problems at the university. Many of the facilities of these present-day universities are thus called upon to produce high quality and talented graduates, while dealing with less infrastructure, fewer research facilities, and minimal instructional support. Considering these circumstances, effective teaching and research are obviously impossible.

In the light of turning the disadvantaged past into a future of human development, two types of messages are equally important. First of all, educational policy should enable learners with academic talents to be given a chance to pursue their studies in higher education. More initiative should be taken to make this possible. Secondly, and at the same time, one should create better conditions for a much wider spectrum of vocational educational and training tracks to enable learners to develop their potential and eventually find their place in society. It should be possible to change tracks, if appropriate, not only from the vocational to the academic, but also the other way around. Moreover, we should create more forms of combining a job and learning (which is called dual learning), so learners would be able, after a certain period of working, to return to an educational track to enhance their knowledge and skills. And equally important is that those people who were denied any form of education in the past be given the opportunity through recognition of their prior learning (RPL) to get involved in skills training and education (Van der Kamp, 2006). Despite a lack of formal education, some individuals have gained rich practical skills and life experiences through informal learning. The man from Ga-Mothapo could, for instance, be qualified to take part in skills training for welding at the nearby Technicon.

In other words, to deal with the demands and dynamics of the formal and informal labour market, as well as the enhancement of active citizenship, increasingly a lifelong and lifewide learning approach is needed, also at the universities (see Jarvis, 2007). By such a differentiated and flexible approach, it might be possible to overcome the growing divide between the so-called educated and uneducated, a divide which forms an enormous threat to the democratic quality and stability of any society.

\section{Conclusion}

The road to a quality African university excelling in teaching, research, and community outreach is a long and winding one. One thing we know for sure is that appealing mission statements alone will not help. And what is more disturbing: the dynamics discussed in this article are pushing the universities further away from accomplishing their mission statements. The system of education in general, and higher education in particular, is highly dysfunctional in terms of wasted human capacity as well as financial resources. African higher education institutions cannot close their eyes to the immense skills shortage and the frightening percentages of youth unemployment. It is time, therefore, to work much more gravely and continuously - step by step - on the implementation of well-planned and appealing intentions. Clearly, it is the responsibility of universities to generate innovative and practical knowledge, to prepare students adequately as active citizens for the labour market, to contribute to the developments of communities and to foster critical thinking. These challenges need to be given high priority.

\section{References}

Al-Samarrai, S. \& Bennell, P. (2006). Where has all the education gone in Sub-Saharan Africa? Employment and other outcomes among secondary school and university leavers. Brighton: Institute of Development Studies at the University of Sussex.

Altbach, P. G. \& Peterson, P. M. (1999). Higher Education in the $21^{\text {st }}$ Century: Global Challenge and National Response. IIE Research Report No. 29. New York: Institute of International Education; Boston College Center for International Higher Education.

Amenumey, D. E. K. (Ed.) (2007). Challenges of Education in Ghana in the 21st Century. Accra, Ghana: Woeli. 
Angucia, M. (2010). Broken Citizenship. Formerly abducted children and their reintegration in northern Uganda. Amsterdam: Rozenberg Publishers.

Boog, B., Preece. J., Slagter, M., \& Zeelen, J. (Eds.) (2008). Towards quality improvement of Action Research: developing ethics and standards. Taipei/Rotterdam: Sense Publishers.

Bourdieu, P. (1991). Language and symbolic power. Harvard: University Press.

Bruneforth, M. (2010). Higher education in sub-Saharan Africa - A Statistical Portrait. UNESCO: UIS Workshop on education statistics. Windhoek, 17-21 October, 2010.

Castells, M. (2001). Universities as dynamic systems of contradictory functions. In: Muller, J., Cloete, N., \& Badat, S. (Eds.) Challenges of Globalisation. South African debates with Manuel Castells. Cape Town: Maskew Miller Longman, pp. 206-223.

Freire, P. (1972). Pedagogy of the Oppressed. Harmondsworth: Penguin.

Kanyandago, P. (2010). Revaluing the African endogenous education system for community based learning: an approach to early school leaving, In: Zeelen J., Van der Linden J., Nampota, D. \& Ngabirano, M. (Eds.) The burden of educational exclusion. Understanding and challenging early school leaving in Africa. Rotterdam/Boston/Taipei: Sense Publishers, pp. 101-116.

Jahn, A. \& Zeelen, J. (2003). Country report on the status and needs of Higher Education in Tanzania. Preparatory study for a Higher Education Cooperation programme between the EU and ACP (Africa, Caribbean and Pacific) countries, commissioned by the Coimbra Group of European universities.

Jansen, J. (2002). Changing institutional research cultures: Lessons learned from experiences. Quality review of education and training in South Africa, 8(2): 47-57.

Jarvis, P. (2007). Lifelong learning and the learning society. Vol. 1, Towards a comprehensive theory of human learning. Vol.2, Globalisation, lifelong learning and the learning society. Vol. 3, Democracy, lifelong learning and the learning society. London: Routledge.

Kasozi, A.B.K. (2010). The State of Higher Education and Training in Uganda 2010: A Report on higher education delivery and institutions. Kampala: National Council for Higher Education.

Kibwika, P. (2006). Learning to make change. Developing innovation competence for creating the African university of $21^{s t}$ century. Wageningen: Academic Publishers.

Langworthy, A. (2008). Skills and knowledge for the future: Why universities must engage with their communities. The Australasian Journal of Community Engagement; 2(2): 57-72.

Lebeau, Y. (2008). Universities and social transformations in sub-Saharan Africa: global rethoric and local traditions. Compare: A journal of Comparative and International Education 38 (2): 139-153.

Lewin, K.M. \& Akyeampong, K. (2009). Education in sub-Saharan Africa: researching access, transitions and equity. Comparative Education 45 (2), 143-150. http://dx.doi.org/10.1080/03050060902920492

Lewin, K.M. (2009). Access to education in sub-Saharan Africa: Patterns, problems and possibilities. Comparative Education 45 (2), 151-174. http://dx.doi.org/10.1080/03050060902920518

Mamdani, M. (2007). Scholars in the Marketplace. The dilemmas of Neo-Liberal Reform at Makerere University, 1989-2005. Kampala: Fountain Publishers.

Mkude, D., Cooksey, B., \& Levey, L. (2003). Higher Education in Tanzania. A case study. Dares-Salaam: Mkuki na Nyota Publishers.

Mail \& Guardian, 10 Jan. 2012.

Mhina, A., \& Killian, B. (2009). REDET: Internal Evaluation of REDET: Outputs, Outcomes and Impacts. Phase I-V (1992 - 2007). Dares-Salaam: University of Dares-Salaam.

Minnis, J.R. (2006). Non-formal education and informal economies in Sub-Saharan Africa: finding the right match. Adult Education Quarterly 56 (2), 119-133. http://dx.doi.org/10.1177/0741713605283432

Mollel, H.A. (2010). Participation for local development. The reality of decentralisation in Tanzania. Leiden: African Studies Centre.

Mulenga, D.C. (2001). Mwalimu Julius Nyerere: a critical review of his contributions to adult education and postcolonialism. International Journal of Lifelong Education 20 (6), 446-470. http://dx.doi.org/10.1080/02601370110088436

Musisi, N. \& Muwanga, N. (2003). Makerere University in Transition 1993 - 2000. Opportunities and Challenges. Kampala: Fountain Publishers. 
Mwinzi, D. \& Kelemba, J.K. (2010). Access to and retention of early school leavers in basic technical education in Kenya. In: Zeelen, J., Van der Linden, J., Nampota, D., Ngabirano, M. (Eds.), The Burden of Educational Exclusion. Understanding and Challenging Early School Leaving in Africa. Sense Publishers, Rotterdam, pp. 317-338.

Nyerere, J. K. (1968). Freedom and Socialism. A Selection from Writings \& Speeches, 1965-1967, Dar-es-Salaam: Oxford University Press.

Rampedi, M.A. (2003). Implementing Adult Education Policy in the Limpopo Province of South Africa: Ideals, Challenges and Opportunities. Groningen: Centre for Development Studies.

Ramphele, M. (2002). Steering by the stars. Being young in South Africa. Cape Town: Tafelberg Publishers.

Openjuru, G. (2010). Government education policies and the problem of early school leaving : the case of Uganda. In: Zeelen, J., Linden, J., van der, Nampota, D., Ngabirano, M. (Eds.). The burden of educational exclusion. understanding and challenging early school leaving in Africa. (pp. 22-47). Rotterdam/Taipei/Boston: Sense Publishers.

Ramani, E. \& Joseph, M. (2002). Breaking new ground: Introducing an African language as medium of instruction at the University of the North. Perspectives in Education, Volume 20, Nr. 1, pp. 233-241.

Sawyerr, A. (2002). Challenges facing African Universities. Selected Issues. Unpublished study presented at the 2002 ASA (African Studies Association) conference.

Sitoe, A. (2006). Epistemological Beliefs and Perceptions of Education In Africa. An explorative Study with High School Students in Mozambique. Groningen: Centre for Development Studies.

Stevens, H. (2000). Functional (il)literacy in a changing South Africa. UNIN Adult Education Series, volume 1. Polokwane: Lamprint.

Teferra, D. \& Altbach, P.G. (2004). African higher education: Challenges for the $21^{\text {st }}$ century. Higher Education 47: 21-50. http://dx.doi.org/10.1023/B:HIGH.0000009822.49980.30

UNESCO. (2011). The hidden crisis: Armed conflict and education. EFA Global Monitoring Report 2011. Paris: UNESCO Publishing.

United Nations. (2004). World Population to 2300. New York: United Nations Department of Economic and Social Affairs (ESA). Population Division.

Van der Kamp, M. (2006). The contribution of APEL to Lifelong Learning. In C. Corradi, N. Evans \& A.Valk (Eds.). Recognising Experiential Learning, pp. 220-233. Tartu: University of Tartu Press. http://dx.doi.org/10.1080/02601370500169723

Van der Veen, R. \& Preece, J. 2005. Poverty reduction and adult education: beyond basic education. International Journal of Lifelong Education 24 (5), 381-391.

White, C. (1997). From despair to hope: The Turfloop experience. Turfloop: University of the North, University Press.

World Bank. (2002). Constructing Knowledge Societies: New Challenges for Tertiary Education. Washington D.C.: World Bank.

World Bank. (2009). Annual report. Washington D.C.: World Bank.

Zeelen, J. (2003). Improving the research culture at historically black universities: The situation at the University of the North. Perspectives in Education 21 (2): 137-149.

Zeelen, J. (2004). From Social Exclusion to Lifelong Learning: research results, challenges and perspectives. Farewell address. Monograph, Turfloop: University of Limpopo.

Zeelen, J. \& Van der Linden, J. (2009). Capacity building in Southern Africa: experiences and reflections: towards joint knowledge production and social change in international development cooperation. Compare: A Journal of Comparative and International Education 39 (5): 615- 628.

Zeelen, J., Van der Linden, J., Nampota, D., Ngabirano, M. (Eds.) (2010). The burden of educational exclusion. Understanding and challenging early school leaving in Africa. Taipei/ Rotterdam/Boston: Sense Publishers. 